\title{
Lower-order and Higher-order Reading Questions in Secondary and University Level EFL Textbooks in Jordan
}

\author{
Nasser M. Freahat \\ English Language Department, Al-Imam Mohammad Ibn Saud Islamic University, Riyadh, Saudi Arabia \\ Oqlah M. Smadi \\ Department of Curricula and Instruction, Yarmouk University, Irbid, Jordan
}

\begin{abstract}
The purpose of this study was to analyze thinking levels of the reading comprehension questions in Action Pack 11 (hereafter AP 11) which is taught for grade 11, Action Pack 12 (hereafter AP 12) that is taught for grade 12 at the schools of The Jordanian Ministry of Education and New Headway Plus Pre-intermediate (hereafter NHWP) that is taught for the first English language course taught at Yarmouk University. All WHquestions in the three textbooks analyzed according to Bloom's Taxonomy. The researchers calculated the percentages and frequencies of the cognitive levels of the questions in the three textbooks. Chi square $(\chi 2)$ was used to draw comparisons between the cognitive levels of the questions. The results indicated that low-level questions are dominant in the three. It was also found that low-level questions were dominant in both stages. An interesting conclusion was that the reading material of the university textbook does not show a higher level of thinking. On the contrary, the reading content in the high school textbooks revealed more concentration on higher-level thinking questions. As a result, the study recommended that there should be more communication between secondary schools and universities to bridge the gap between them.
\end{abstract}

Index Terms - higher-order questions, lower-order questions, EFL textbooks, University reading, secondary reading

\section{INTRODUCTION}

Questioning is one of the most regularly employed teaching strategies by teachers and in textbooks. Good questions lead to good understanding. Questions serve as means of organizing knowledge, or correlating the results of educative experience (Underhill, 1991). There is no doubt about the importance of questioning as an instructional method for teaching reading. Textbook questions can be used for academic evaluation as well as the development of various skills. The cognitive level of questions develops the interaction between the students and the text. Therefore, the types of questions should take into consideration the different ability levels among students. Therefore, it is necessary to analyze the aspect of questions in textbooks in order to assess how these textbooks develop students' thinking.

Reading comprehension questions have been classified into various taxonomies. A variety of classification systems have been used to determine the levels of questions asked by textbooks. In general, these categories have sorted questions on the two major categories: lower- level questions and higher-level questions. Lower level questions emphasize the recall of specific and universal methods, processes, structures, and settings. Higher-level questions, on the other hand, are more advanced and require knowledge of subject matter. Moreover, they require students to engage on deeper thinking processes.

Bloom (1956) developed a taxonomy for categorizing questions and responses. This taxonomy includes the following elements: Knowledge: recalling specifications; Comprehension: describing in one's words; Application: applying information to produce results; Analysis: subdividing something to show how it is put up together; Synthesis: creating a unique product; and Evaluation: making value decisions about issues. The first three levels deal with lower-order thinking skills whereas the last three employ higher-order thinking skills (Hopper, 2009). Barrett and Smith (1979) adapted Bloom's taxonomy to provide a classification of reading objectives and suggested educational goals for reading instruction. Four objectives were classified: 1) Literal meaning 2) Inference 3) Evaluation 4) Appreciation.

Pearson and Johnson (1978) claimed that comprehension is best understood by employing the "new to known" principle. Pearson and Johnson taxonomy is a three-level taxonomy. The three categories are textually explicit, textually implicit, and script implicit. Several studies have applied these taxonomies to the examination of comprehension questions.

Davies and Widdowson (cited in Williams and Moran, 1989) classified questions into direct reference questions, inferences, and supposition and evaluation questions. Furthermore, Barrette (cited in Williams and Moran, 1989) distinguished five types of questions: internal comprehension, recognition of the ideas in the text, inferential ability, evaluation, and appreciation. 
Researchers who studied the influence of lower- and higher-level questions on students' achievement have obtained mixed results. Research has also shown conflicting conclusions regarding the effect of using different cognitive levels of questions on students' achievement. Carlsen (1991) and Ghall and Rhody (1987) have categorized several reasons for these contradictory factors. Among the reasons was that researchers used different question classification systems. They recommended that both lower- and higher-level questions should be used. Lower-cognitive questions are employed to review basic facts and skills whereas higher-level questions promote critical thinking ability and skills.

\section{A. Statement of the Problem}

A number of university students in Jordan suffer from apparent difficulties in comprehending English texts. They fail to deal with the whole text as a unit. This weakness impairs their utilization of texts within and outside the academic context (Al Haddad, 1996). The deficiency in the students' reading can be attributed to different factors including the preparation of the students at school and the gap between the school and the university textbooks. Hussein (2012) maintains that Jordanian first year students lack many "reading comprehension skills" which they need to understand fully a piece of writing. For instance, he complains that, they lack the ability to answer questions that demand the possession of skills involving deep thinking. He adds that little attention is given to skills which belong to inferential and critical levels. To ascertain whether there is a textual gap or not it requires that the content of textbooks prescribed for students be analyzed. This study sheds some light on the connection between high school stage EFL textbooks and an introductory university EFL textbook with respect to the thinking levels demonstrated by the reading comprehension questions.

The nature of textbook questions has received frequent attention. Research on this area has shown that there is a preponderance of lower-level questions in the textbooks in general and in reading textbooks in particular (Rawadieh, 1998; Sunggingwati, 2003, Alul, 2005; Ewies, 2010; Igbaria, 2013). These questions tend to develop students' abilities to memorize facts, but not to think critically. In spite of the continual calls for employing higher-level questions for enhancing the development of critical thinking and problem solving skills, research has not shown any marked increase in the higher cognitive levels. This study was designed to use Bloom's taxonomy to analyze types of the reading questions in the Jordanian high school stage and university first year textbooks. This was done to determine if there were significant differences among these English Language textbooks at the two stages in the distribution of lower-level questions (knowledge, comprehension and application) and higher-level questions (analysis, synthesis and evaluation). In other words, this study addressed the following questions:

1. To what extent are the WH-questions in the cognitive domain of Bloom's Taxonomy varied or frequent in the First Secondary Grade EFL textbook in Jordan (Action Pack 11), the Second Secondary Grade EFL Textbook in Jordan (Action Pack 12) and Preparatory English Language textbook at Yarmouk University (New Headway Plus Preintermediate)?

2. Do the high school stage textbooks (Action Pack 11 and Action Pack 12) and first year preparatory English language course textbook (New Headway Plus Pre-intermediate) differ in the proportions of lower- and higher levelreading questions?

\section{B. Purpose of the Study:}

The study aimed to analyze thinking levels of the reading comprehension questions in Action Pack 11 which is taught for grade 11, Action Pack 12 that is taught for grade 12 at the schools of The Jordanian Ministry of Education and New Headway Plus Pre-intermediate that is taught for the first English language course taught at Yarmouk University. The study also aimed to compare thinking levels of the reading comprehension questions in the high school stage EFL textbooks in Jordan (Action Pack 11 and 12) to those demonstrated in a first year university EFL textbook in Jordan (New Headway Plus Pre-intermediate).

\section{Significance of the Study}

The study becomes more important when one considers the importance of the transitional period between the last year at school and the first year at university. The findings of this study are significant for those who are concerned with teaching reading comprehension in high schools and at universities, selecting EFL courses, and evaluating students' performance in reading. The importance of the study also stems from the importance of questioning and textbook questions as an instructional method in teaching the reading skills and critical thinking. Furthermore, the study is significant because it compares the thinking levels demonstrated by the textbooks in two stages; the high school stage and the first year at university. The study also sheds light on how smooth and logical the transition from school to university is with regards to the thinking levels of the reading comprehension stages.

\section{Context of the Study}

In Jordan, English is the dominant foreign language taught at the basic stage, high school stage, and at universities. EFL instruction in Jordan begins at Grade 1 and extends to grade 12 and continues as a compulsory subject throughout the whole school system. The average number of hours given to English is five hours a week at the basic stage and four hours a week at the high school stage for each class. At the conclusion of the high school stage which includes grades 
11 and 12, students have to sit for an exam known as The General Certificate Exam or "Tawjihi". Performance in the English language subject of this exam with the other subjects is determinant for university enrollment.

Textbooks, in Jordan, are considered an essential tool for teaching and learning. In some cases, textbooks are the only available reading material for students. The teaching of English as a Foreign Language in Jordan is an important objective which aims at developing different language skills. As a natural learning environment is unavailable for Jordanian students, their major source to acquire reading comprehension is through classroom instruction of the assigned EFL textbooks. The importance of EFL textbooks entails that these textbooks should be evaluated to make sure they are suitable for the level of the learners. Furthermore, EFL textbooks should also be evaluated to make sure that the suitable language skills are tackled properly. An important feature that should be evaluated is the transition from one stage to the other. The current study investigates the levels of thinking demonstrated by reading comprehension questions in three textbooks in two different stages and how logical the sequence of these levels from one stage to the other is.

In the academic year 2009/2010, the Jordanian Ministry of Education introduced "AP 11 " and in the academic year 2010/2011, AP 12 was introduced. The AP series is a twelve- level EFL course for Jordanian students leading them from the basic stage to the high school stage. The series is based on the most modern methods of teaching language which combines a topic- based approach with functional language practice. Careful attention is given to a comprehensive skills syllabus (Lambert, 2010). Action Pack series is developed by the Educational Research Center and Published by York Press. AP 11 and 12 are written by Simon Haines.

On the other hand, Jordanian Universities use different EFL textbook series for teaching the compulsory EFL courses. One of these series is New Headway Plus. This series was introduced at Yarmouk University and at other Jordanian universities recently. The authors said that the New Headway Plus series is an attempt to guide students to an understanding of new languages rather than just having examples of it on the page. The aim of teaching reading activities according to the teacher's book is to develop students' ability to read for gist and specific information, to expand vocabulary around the topic, and to encourage lots of fluency-based speaking practice. New Headway Plus Preintermediate is taught in the first introductory course at Yarmouk University.

The researcher selected New Headway Plus Pre-intermediate textbook for analysis because it is the first course taught for first year students (English 099). On the other hand, Action Pack 11 and Action Pack 12 were selected because they are the two EFL textbooks taught at the high school stage in Jordan. The researcher assumes that when moving from the high school stage to the university level, focus should be more on higher- level reading comprehension questions and less on lower-level reading comprehension questions.

\section{REVIEW OF RELATED LITERATURE}

Literature has demonstrated that there is a lack of higher-level questions and preponderance of lower-level questions in most of English Language textbooks prescribed for students. However, as far as the researcher is interested, no research has focused on the application of the taxonomy in EFL reading instruction or assessment. In one of the studies that analyzed the cognitive levels of questions in the textbooks of the Ministry of Education in Jordan, Rawadieh (1998) analyzed the types of questions in Jordanian secondary social studies textbooks according to Bloom's cognitive taxonomy to determine whether significant differences is existed among these textbooks in the distribution of lower level questions and higher level questions or not. The total number of the analyzed questions was 822. The results revealed that the four textbooks presented significantly more lower-level questions than higher- level questions. The results also showed that the twelfth grade textbooks gave less emphasis to higher level questions than did eleventh grade textbooks. The findings also showed that the authors of the Jordanian social studies textbooks were familiar with various types and levels of questions so that they followed similar questioning patterns in the textbooks.

The predominance of lower- level questions seems a worldwide problem. For example, Rinser, Nicholson, and Web (2000) used Bloom's taxonomy to determine the levels of questioning granted by two series of third grade social studies textbooks namely, Communities: Harcourt Brace Social Studies: 2000, and Communities: McMillan- McGrew Social Studies: 1997. The study examined the extent to which each selected textbook emphasized higher and lower levels of questioning. Three raters classified the questions using the six major categories of Bloom's taxonomy. It was found that elementary students exposed to the textbooks would have opportunities, as encouraged by the questions included in the textbooks, to understand, apply, synthesize, and evaluate social concepts. It was also shown that in order to answer the majority of questions in the textbooks, students must demonstrate higher cognitive abilities such as application and evaluation. Moreover, the study found that Harcourt Brace was superior to McMillan in the area of higher level questioning. When a textbook is written or adopted for a certain context, thinking levels demonstrated by the book need to be taken into consideration. As proved earlier, the inclusion of the various levels of thinking helps the learner master various thinking skills.

Similarly, Sunggingwati (2003) analyzed all the questions in junior high school English language textbooks. The textbooks analyzed were "Let's learn English 1,2, and 3." The researcher used Barret's taxonomy for evaluating reading comprehension questions which has four levels of comprehension (literal, inferential, evaluation, and application). The study found that the levels of reading questions in the analyzed textbooks covered only three levels of reading comprehension based on Barrett's taxonomy namely, literal, influential, and evaluation. Therefore, the 
application level was not represented in the textbooks. This indicates that the thinking levels are not perfectly taken into consideration when the books have been published as the author concludes.

In another study, Alul (2005) used Bloom's Taxonomy to evaluate the instructional questions in the Eighth Grade English Textbooks used in Palestine during the academic year 1999-2000. The researcher prepared an analysis sheet and used keywords in the classification of the questions. Then the researcher computed the number of questions per each cognitive level and calculated lower and higher level questions and tabulated the frequencies and percentages. The results of the study revealed that there was still a preponderance of lower level questions in the studied textbooks.

In one of the most recent studies, Ewies (2010) analyzed the English language Islamic education textbooks for the primary cycle in the United Arab Emirates. The questions in the textbooks were analyzed using a tool that the researcher developed employing Bloom's cognitive taxonomy. In regard of the distribution of the questions over the cognitive aspect, the study revealed that $36 \%$ of the questions involved higher-level thinking whereas $64 \%$ of the questions involved lower-level thinking.

In the same year, Riazi and Mosalanejad (2010) investigated the types of learning objectives represented in Iranian senior high school and pre-university English textbooks using Bloom's taxonomy of learning objectives. Three highschool textbooks and a pre-university textbook were included in the analysis. In a ddition to the comprehension questions, the exercises and tasks of the textbooks were codified and the frequencies and percentages of occurrence of different learning objectives were calculated. Results of the study indicated that in all grades lower-order cognitive skills were more prevalent than higher order ones. Furthermore, the difference between the senior high school and the pre-university textbooks in terms of the levels of the taxonomy were significant as the pre-university textbook used some degrees of higher-order learning objectives.

Most recently, Igbaria (2013) examined the variety in the cognitive level represented by the WH-questions in "Horizons" textbook according to Bloom's Taxonomy. The results showed that 244 questions emphasized levels of cognition representing lower-order thinking skills, while only 137 questions emphasized the three higher-order thinking skills. The study also found that the questions in the "Horizons" textbook placed a great deal of emphasis on comprehension, which is one of the lower order thinking skills.

According to the literature reviewed, several conclusions can be made. First, an effective means of stimulating critical thinking skills could be developed through questioning. Second, research results continue to support the importance of questioning in facilitating high levels of thinking. Third, the analyses of the questions indicated that most textbooks emphasized lower-level thinking questions on the expense of higher- level thinking questions. Fourth, a balanced mixture of lower- and higher- level questions seems to be the most appropriate technique for improving students' achievement. Moreover, neglecting higher-level questions in reading textbooks will limit students' thinking skills and replace them with factual memorization skills instead.

Reviewing the literature related to the analysis of the reading comprehension questions according to Bloom's Taxonomy, the researcher found that few studies tackled this issue in Jordan. The literature review helps shows that the validity and reliability of the instrument of this study have been obtained. However, to the best o the researchers' knowledge, no study has investigated the levels of comprehension questions in the two stages of high school and university.

\section{METHODOLOGY}

The appropriate procedure for the purposes of the present study is the descriptive content analysis style which describes the phenomenon and monitors the occurrence of the categories of analysis accurately. All open-ended reading comprehension questions in Action Pack 11, Action Pack 12 and New Headway Plus Pre-intermediate were categorized in light of the cognitive levels of Bloom's Taxonomy of educational objectives. A checklist was prepared to analyze the cognitive levels of all open-ended reading comprehension questions in the three textbooks. Moreover, the list of behavioral verbs appropriate for the levels of Bloom's taxonomy (the cognitive domain) were also used clarifying the process of classification.

\section{A. Choice of the Textbook Level for Analysis}

For a number of reasons, the reading content in grade 11, grade 12, and an introductory University EFL course (LC 099) were chosen as the levels of textbooks to analyze. Grade 11 and 12 represent the English language textbooks prescribed for students at the high school stage in the Jordanian educational system while LC 099 is the first EFL course that the majority of the university freshmen study if compared to other courses. The period including the high school stage and university first year represents the transition from school to university. The researcher was interested in this stage when he planned his research as this stage is a crucial one in the students' academic life and it has not been studied as shown by the literature review. Therefore, it is hoped that this study presents an insight into some aspects of this stage by investigating the appropriateness and the difficulty level of the reading content in the textbooks under study.

\section{B. Validity of the Analysis}


To establish the validity of content analysis, the researcher defined the concepts operationally, prepared the criteria, units and the categories for analyzing the three books. The researcher consulted some experts in the field of language teaching who had experience in content analysis and there was agreement among the experts on the procedure. Moreover, the validity of Bloom's taxonomy has been obtained through theoretical and experimental modes. Research studies in various curriculum areas have supported the structure and content validity of the taxonomy.

\section{Reliability of the Content Analysis}

To verify the intra-rater reliability of the analysis, the researcher analyzed a random sample of the questions with the percentage of $5 \%$ of the total number of the analyzed questions twice. The researcher then computed Scott coefficient between the two analyses. The retrieved reliability coefficient between the two analyses was 0.94 which is considered high. Moreover, to verify the inter-rater reliability of the analysis, another analyst was asked to conduct the analysis using the same categories and units of analysis. The second analyst was acquainted with the procedure. The two analyses were done separately on the same sample of questions. The inter-rater reliability coefficient was calculated and it was found 0.93 which is considered high.

\section{Data Analysis}

To answer the study questions, the primary data collected from the textbooks under study were approached through descriptive and inferential analysis. The descriptive analysis included classifying all questions according to the six categories of the cognitive level of Bloom's taxonomy, calculating frequencies, and reporting percentages in each textbook. All data were presented in tabular forms. Results of the data were then divided into lower and higher-level categories and percentages were computed to determine the extent to which the reading comprehension questions in the high school stage textbooks (Action Pack 11 and Action Pack 12) and university stage textbook (New Headway Plus Pre-intermediate) emphasize both lower- and higher-levels of questions. All data which originated from descriptive analysis, such as frequencies and percentages, were utilized in the inferential component of data analysis. The statistical procedure of Chi square $(\chi 2)$ cross tabulation was used to determine if the reading content in Action Pack 11, Action Pack 12, and New Headway Plus Pre-intermediate differ in the proportions of lower-and higher-level questions.

\section{RESULTS AND ANALYSIS}

The results of the study are presented according to the order of the study's questions respectively:

Results related to the first question: To what extent are the WH-questions in the cognitive domain of Bloom's Taxonomy varied or frequent in the First Secondary Grade EFL textbook in Jordan (Action Pack 11), the Second Secondary Grade EFL Textbook in Jordan (Action Pack 12) and Preparatory English Language textbook at Yarmouk University (New Headway Plus Pre-intermediate)?

The three textbooks under study contained varied numbers of questions as follows: $A P 11$ included 58 questions, AP12 included 57 questions, and NHWP included 183 questions. 298 questions were obtained from the three textbooks.

In order to offer an answer to this question, which focused on analyzing the proportions of lower- and higher-level questions, the researcher analyzed the cognitive levels of the questions found in the textbooks under study. Comparisons were also made between proportions of the questions in each of the three textbooks, and then comparisons were made between the proportions of the cognitive levels of the questions at both stages; high school stage including Action Pack 11 and Action Pack 12 and the university stage represented by the New Headway Plus Pre-intermediate.

In addition, frequencies of the questions included in the three textbooks under study were calculated according to Bloom's Cognitive Levels. The percentages of the questions among these levels in each textbook were calculated in addition to calculating the adjusted residual where needed in light of Chi Square Test for Independence, taking into account that the cognitive level "synthesis" was excluded because it had not been noticed in any of the three textbooks under study. The data are presented in Table 1. 
TABLE 1:

FREQUENCIES AND PERCENTAGES OF READING COMPREHENSION QUESTIONS ACCORDING TO BLOOM'S TAXONOMY OF EDUCATIONAL OBJECTIVES IN $A P 11, A P 12$, AND NHWP AND RESULTS OF $X^{2}$ TEST OF INDEPENDENCE REGARDING TEXTBOOK

\begin{tabular}{|c|c|c|c|c|c|c|c|}
\hline \multirow[b]{2}{*}{ Text Book } & \multirow[b]{2}{*}{ Statistic } & \multicolumn{5}{|c|}{ Bloom's Levels } & \multirow[b]{2}{*}{ Total } \\
\hline & & 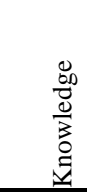 & 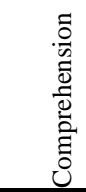 & 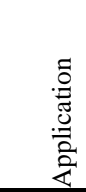 & 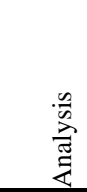 & 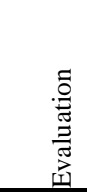 & \\
\hline \multirow[t]{3}{*}{$A P 11$} & Count & 20 & 7 & 13 & 17 & 1 & \multirow{3}{*}{$\begin{array}{l}58 \\
100.0\end{array}$} \\
\hline & $\%$ within Text Book & 34.5 & 12.1 & 22.4 & 29.3 & 1.7 & \\
\hline & Adjusted Residual & 0.166 & -4.065 & 1.830 & 3.152 & 0.610 & \\
\hline \multirow[t]{3}{*}{$A P 12$} & Count & 9 & 24 & 14 & 9 & 1 & \multirow{3}{*}{$\begin{array}{l}57 \\
100.0\end{array}$} \\
\hline & $\%$ within Text Book & 15.8 & 42.1 & 24.6 & 15.8 & 1.8 & \\
\hline & Adjusted Residual & -3.159 & 1.269 & 2.318 & 0.004 & 0.629 & \\
\hline \multirow[t]{3}{*}{$N H W P$} & Count & 71 & 73 & 17 & 21 & 1 & \multirow{3}{*}{$\begin{array}{l}183 \\
100.0\end{array}$} \\
\hline & $\%$ within Text Book & 38.8 & 39.9 & 9.3 & 11.5 & 0.5 & \\
\hline & Adjusted Residual & 2.417 & 2.280 & -3.361 & -2.567 & -1.004 & \\
\hline \multirow{2}{*}{ Total } & Count & 100 & 104 & 44 & 47 & 3 & 298 \\
\hline & $\%$ within Text Book & 33.6 & 34.9 & 14.8 & 15.8 & 1.0 & 100.0 \\
\hline$\chi^{2}$ & & \multicolumn{2}{|c|}{$\mathrm{N}$ of Cases } & $\overline{\mathrm{Df}}$ & & \multicolumn{2}{|l|}{ Sig. } \\
\hline \multicolumn{2}{|l|}{37.291} & \multicolumn{2}{|c|}{298} & 8 & & \multicolumn{2}{|l|}{0.000} \\
\hline
\end{tabular}

Table 1 shows a significant relation between the textbooks and Bloom Cognitive levels in relation to the questions contained in the three textbooks. When moving from $A P 11$ to $N H W P$, a decline is noticed in the analysis level in $A P 11$, and when moving from $A P 11$ to $A P 12$ to $N H W P$, a decline is noticed in the level of application with a huge increase in the levels of knowledge and comprehension levels in $N H W P$. Table 1 also indicates that the questions were presented in the following order according to their inclusion: in AP11 (knowledge, analysis, application, comprehension, and evaluation), AP12 (comprehension, application, knowledge, analysis, and evaluation) and New Headway Plus Preintermediate (comprehension, knowledge, analysis, application, and evaluation).

Moreover, frequencies of the questions included in the three textbooks under study were calculated according to Bloom's Thinking levels (Low-level questions and high-level questions). The percentages of the questions among these two levels in each textbook were calculated in addition to calculating the adjusted residual where needed in light of Chi Square Test for Independence, taking into account that the cognitive level "synthesis" was excluded because it had not been noticed in any of the three textbooks under study. The data are presented in Table 2.

TABLE 2:

FREQUENCIES AND PERCENTAGES OF LOWER AND HIGHER LEVEL QUESTIONS IN AP11, AP12, AND NHWP AND RESULTS OF X2 TEST OF INDEPENDENCE REGARDING TEXTBOOK

\begin{tabular}{lllll}
\hline \multirow{2}{*}{ Text Book } & \multirow{2}{*}{ Statistic } & \multicolumn{2}{c}{ Thinking Level } & \multirow{2}{*}{ Total } \\
\cline { 3 - 4 } & & Low & High & \\
\hline \multirow{3}{*}{ AP11 } & Count & 40 & 18 & 58 \\
& \% within Text Book & 69.0 & 31.0 & 100.0 \\
& Adjusted Residual & -3.24 & 3.24 & \\
\hline \multirow{2}{*}{ AP12 } & Count & 47 & 10 & 57 \\
& \% within Text Book & 82.5 & 17.5 & 100.0 \\
& Adjusted Residual & -0.17 & 0.17 & \\
\hline \multirow{2}{*}{ NHWP } & Count & 161 & 22 & 183 \\
& \% within Text Book & 88.0 & 12.0 & 100.0 \\
\hline \multirow{2}{*}{ Total } & Adjusted Residual & 2.77 & -2.77 & \\
& Count & 248 & 50 & 298 \\
\hline$\chi^{2}$ & $\%$ within Text Book & 83.22 & 16.78 & 100.00 \\
\hline 11.431 & N of Cases & & Df & Sig. \\
\hline
\end{tabular}

Table 2 shows that there is a relation between the textbook and the level of thinking. This can be noticed when moving from Action Pack 11 to New Headway Plus Pre-intermediate an incline is noticed in the percentage of the higher-level questions and an increase is noticed in the percentage of the lower-level questions. Table 2 also shows that the low-level questions are dominant in the three textbooks with percentages of $69.0 \%$ for Action Pack 11, 82.5\% for Action Pack12, and $83.22 \%$ for New Headway Plus Pre-intermediate.

Results related to the second question: Do the high school stage textbooks (Action Pack 11 and Action Pack 12) and first year preparatory English language course textbook (New Headway Plus Pre-intermediate) differ in the proportions of lower- and higher level- reading questions?

Frequencies of the questions included in the three textbooks of the two stages (High school and university) under study were calculated according to Bloom's Cognitive Levels. The percentages of the questions among these levels in each textbook were calculated in addition to calculating the adjusted residual where needed in light of Chi Square Test 
for Independence, taking into account that the cognitive level "synthesis" was excluded because it had not been noticed in any of the three textbooks under study. The data are presented in Table 3.

TABLE 3:

FREQUENCIES AND PERCENTAGES OF COMPREHENSION QUESTIONS ACCORDING TO THE BLOOM'S TAXONOMY OF EDUCATIONAL OBJECTIVES IN UNIVERSITY AND HIGH SCHOOL STAGE TEXTBOOKS AND RESULTS OF X2 TEST OF INDEPENDENCE REGARDING STAGE

Bloom's Levels

\begin{tabular}{|c|c|c|c|c|c|c|c|}
\hline Stage & Statistic & $\begin{array}{l}0 \\
\frac{0}{0} \\
\frac{0}{3} \\
0 \\
\vdots \\
\underline{\Xi}\end{array}$ & 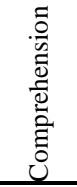 & 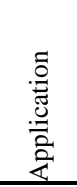 & 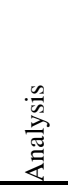 & 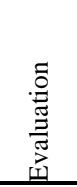 & Total \\
\hline \multirow[t]{3}{*}{ High school } & Count & 29 & 31 & 27 & 26 & 2 & \multirow{3}{*}{$\begin{array}{l}115 \\
100.0\end{array}$} \\
\hline & $\%$ within stage & 25.2 & 27.0 & 23.5 & 22.6 & 1.7 & \\
\hline & Adjusted Residual & -2.42 & -2.28 & 3.36 & 2.57 & 1.00 & \\
\hline \multirow[t]{3}{*}{ University } & Count & 71 & 73 & 17 & 21 & 1 & \multirow{3}{*}{$\begin{array}{l}183 \\
100.0\end{array}$} \\
\hline & $\%$ within stage & 38.8 & 39.9 & 9.3 & 11.5 & 0.5 & \\
\hline & Adjusted Residual & 2.42 & 2.28 & -3.36 & -2.57 & -1.00 & \\
\hline \multirow[t]{2}{*}{ Total } & Count & 100 & 104 & 44 & 47 & 3 & 298 \\
\hline & $\%$ within stage & 33.6 & 34.9 & 14.8 & 15.8 & 1.0 & 100.0 \\
\hline \multicolumn{2}{|l|}{$\chi^{2}$} & \multicolumn{2}{|c|}{$\mathrm{N}$ of Cases } & Df & & \multicolumn{2}{|l|}{ Sig. } \\
\hline 23.443 & & \multicolumn{2}{|c|}{298} & 4 & & \multicolumn{2}{|l|}{0.000} \\
\hline
\end{tabular}

Table 3 shows that there is a significant relation between the academic stage and Bloom's Cognitive Levels. It can be noticed that when moving from the high school stage to the university stage there is a decline in the levels of application and analysis and an increase in the levels of knowledge and comprehension. Table 3 also shows that the thinking levels of knowledge and comprehension were dominant in the two stages with percentages of $25.2 \%, 27.0 \%$ for the high school stage textbooks, and $38.8 \%, 39.9 \%$ for the university textbook respectively. The least number of questions were categorized at the level of Evaluation with percentages of $1.7 \%$ for the high school stage and $0.5 \%$ for the university level. Not to mention the level of Synthesis which had not been categorized in any of the two stages. Table 3 also indicates that the questions were presented in the following order according to their inclusion: The High school Stage (comprehension, application, knowledge, analysis, and evaluation), The University Level (comprehension, knowledge, analysis, application, and evaluation).

Finally, frequencies of the questions included in the two stages under study (high school and university) were calculated according to Bloom's Thinking levels (Low-level questions and high-level questions). The percentages of the questions among these two levels in each academic stage were calculated in addition to calculating the adjusted residual where needed in light of Chi Square Test for Independence. The data are presented in Table 4.

TABLE 4:

FREQUENCIES AND PERCENTAGES OF LOWER AND HIGHER LEVEL QUESTIONS IN UNIVERSITY LEVEL AND HIGH SCHOOL STAGE TEXTBOOKS AND

\begin{tabular}{|c|c|c|c|c|}
\hline \multirow{2}{*}{ Stage } & \multirow{2}{*}{ Statistic } & \multicolumn{2}{|c|}{ Thinking Level } & \multirow{2}{*}{ Total } \\
\hline & & Low & High & \\
\hline \multirow[t]{3}{*}{ High school } & Count & 87 & 28 & \multirow{3}{*}{$\begin{array}{l}115 \\
100.0\end{array}$} \\
\hline & $\%$ within stage & 75.7 & 24.3 & \\
\hline & Adjusted Residual & -2.772 & 2.772 & \\
\hline \multirow[t]{3}{*}{ University } & Count & 161 & 22 & \multirow{3}{*}{$\begin{array}{l}183 \\
100.0\end{array}$} \\
\hline & $\%$ within stage & 88.0 & 12.0 & \\
\hline & Adjusted Residual & 2.772 & -2.772 & \\
\hline \multirow[t]{2}{*}{ Total } & Count & 248 & 50 & 298 \\
\hline & $\%$ within stage & 83.2 & 16.8 & 100.0 \\
\hline$\chi^{2}$ & $\mathrm{~N}$ of Cases & & Df & Sig. \\
\hline 7.684 & 298 & & 1 & 0.006 \\
\hline
\end{tabular}

Table 4 shows that there is a significant relation between the academic stage (high school/university) and the level of thinking (low/high). This can be noticed when moving from the high school stage to the university. A decline is noticed in the percentage of the higher level questions and an increase is noticed in the percentage of the lower level questions. Table 4 also shows that low-level questions are dominant in both stages with percentages of $75.7 \%$ in the high school stage textbooks and a percentage of $88.0 \%$ in the university level textbook.

\section{DISCUSSION}

The discussion of the results will be proposed according to the questions respectively. 
The first question focused on analyzing the cognitive levels of thinking demonstrated by the WH-reading questions in Action Pack 11, Action Pack 12, and New Headway Plus Pre-intermediate. The results of this question are shown in Tables 1-4.

An overall conclusion that can be drawn from the results of this analysis was that Jordanian High school Stage EFL textbooks and New Headway Plus Pre-intermediate (taught as a university course of Communication skills for freshmen students) had a dominant emphasis on lower level questions. Sixty nine percent of the questions of AP 11, $82.5 \%$ of the questions of $A P 12$, and $88 \%$ of NHWP questions were classified under lower-level cognitive questions and only $31 \%, 17.5 \%$, and $12 \%$ of $A P 11, A P 12$, and NHWP questions respectively at higher levels. To clarify whether the three textbooks under study led equally to the foregoing results, each textbook was examined by itself.

\section{Action Pack 11}

The analysis revealed that AP11 included a greater proportion of higher-level cognitive questions than the other textbooks understudy. A percentage of $31 \%$ was categorized as higher-level questions and $69 \%$ was categorized as lower-level questions. Although this textbook did not have a balanced distribution of lower- and higher-level questions, it gave more opportunities than the other textbooks for the students to use higher level thinking processes. The concentration of the questions of this textbook was found under the domains of knowledge, comprehension, and analysis with the level of synthesis excluded and the level of evaluation appearing in the textbook only once.

Action Pack 12

The analysis of the comprehension questions in AP12 showed a concentration on lower- level thinking skills. The greatest percentage of questions was comprehension and application with the level of synthesis excluded and the level of evaluation appearing in the textbook only once.

New Headway Plus Pre-intermediate

The analysis revealed that NHWP included a greater proportion of lower-level cognitive questions than the other textbooks. A percentage of $88 \%$ was categorized as lower-level questions and only $12 \%$ was categorized as higher-level questions. Opposite to the expectation, the focus of the reading comprehension questions was under the level of comprehension and knowledge, although a person expects more high-level questions when moving to upper grades.

\section{B. Discussion of the Results of the Second Question}

Do the high school stage textbooks (Action Pack 11 and Action Pack 12) and first year preparatory English language course textbook (New Headway Plus Pre-intermediate) differ in the proportions of lower- and higher level- reading questions?

A comparison of the questioning levels in the two stage textbooks revealed significant outcomes. Table 2 shows that when moving from the high school stage to the university stage there is a decline in the levels of application and analysis and an increase in the levels of knowledge and comprehension. The table also shows that the thinking levels of knowledge and comprehension were dominant in the two stages. It also indicates that the questions were presented in the following order according to their inclusion: the high school stage: comprehension, application, knowledge, analysis, and evaluation; at the university level: comprehension, knowledge, analysis, application, and evaluation. Moreover, the results indicate that when moving from the high school stage to the university, a decline is noticed in the percentage of the higher level questions and an increase is noticed in the percentage of the lower level questions.

The predominance of the lower-level thinking questions, the scarcity of some higher-level questions, and lack of progression of the cognitive level questions among the three textbooks indicate that the textbooks failed to offer enough higher level questions at this stage, taking into consideration that the three textbooks are taught at the end of the high school stage and at the beginning of the university life which needs higher levels of thinking than at school. This shows that there was a tendency in these textbooks to provide questions that are designed to help students to acquire factual knowledge rather than to teach them to think. One can thus conclude that the main objectives of the textbooks were the development of lower-order cognitive skills. Similar to earlier studies (Rawadieh, 1998; Sunggingwati, 2003; Alul, 2005; Ewies, 2010; Riazi and Msalanejad, 2010; Igbaria, 2013), the current study found that the examined textbooks emphasized lower-level thinking questions.

This could be a result of the fact that in the Jordanian educational system, the major emphasis is on acquiring knowledge in the form of memorization, rather than creativity through higher-levels of cognitive skills such as analysis and synthesis. The Secondary General Examination (Tawjihi) exerts a real negative backwash effect in that the students are required to learn exactly what is included in the textbooks without any changes on the part of the learners. That is, learners are motivated to memorize the materials and reproduce them on the exam sheets. As such, students are not asked or given the opportunity to use the language.

Due to this fact, students are not required to analyze, synthesize or evaluate the content of the reading material. The teachers do not feel any need to go through these higher-level cognitive skills and they prefer to have time to teach their students the grammatical points and other lower-level cognitive skills they need for the Tawjihi exam or to familiarize them with direct-answer questions. It is likely that textbook developers have also been affected by this phenomenon and have worked in favour of this objective.

Another result of interest was the similarity between the percentages of thinking levels in the reading content of secondary school and university communication skills EFL textbooks. The reading material of the university textbook does not show a higher level of thinking. On the contrary, the reading content in the school textbooks revealed more 
concentration on higher-level thinking questions. This indicates that New Headway Plus Pre-intermediate textbook is below the level of Action Pack 11 and Action Pack 12 in this regard.

This could be attributed to the fact that the university textbook under study is entitled "Pre-intermediate" and that the high school stage textbooks are presented to the students after ten years of English language learning. Although Action Pack 11 and 12 do not clearly identify the language level they are suitable for, one can expect Grade 11 and Grade 12 students to be at least in the pre-intermediate level which makes them equal in level to or higher than New Head Way Plus Pre-intermediate. Such a fact could be due to the lack of harmony between the Ministry of Education and universities which can motivate textbook developers to revise the high school textbooks to bring them into harmony so that university textbook could use higher cognitive questions and skills.

\section{CONCLUSION AND RECOMMENDATIONS}

One should consider the nature of relationship between lower- and higher- cognitive questions. This relationship can be described as integrative. Lower-level questions can enhance the acquisition of factual knowledge and the foundations for attaining high-cognitive skills. On the other hand, higher-level questions are effective tools for stimulating thinking and developing other cognitive skills such as problem solving and decision making. Clearly, attention should be given to preparing teachers and textbook authors to employ both lower- and higher-level questions in classroom interactions and contents of texts. A balanced mixture of lower- and higher-level questions would contribute to accompanying broad educational goals as well as furnishing learners with knowledge and improving their abilities to think and solve problems.

It can be concluded that the reading part in the Jordanian High school Stage EFL textbooks and the introductory university EFL course textbook had a dominant emphasis on questions that involved lower-level thinking processes. Another interesting conclusion was that the reading material of the university textbook does not show a higher level of thinking. On the contrary, the reading content in the school textbooks revealed more concentration on higher-level thinking questions. Furthermore, The predominance of the lower-level thinking questions, the scarcity of some higherlevel questions, and lack of progression of the cognitive level questions among the three textbooks indicated that the textbooks failed to offer enough higher level questions at this stage, taking into consideration that two textbooks are taught at the end of the high school stage and one at the beginning of the university life which needs higher levels of thinking. This shows that there was a tendency in these textbooks to provide questions that are designed to help students to acquire factual knowledge rather than to teach them to think critically. One can thus conclude that the main objectives of the textbooks were the development of lower-order cognitive skills.

In light of the findings of the study, it is recommended that there should be more communication between high schools and universities to bridge the gap between schools and universities with regard to reading comprehension questions, and to enable schools prepare the students for the expected reading demands at the university level. This articulation mainly includes the expected reading level, the desired reading skills, and the suitable materials to achieve these purposes. It is also recommended that Jordanian EFL teachers and instructors do not solely depend on the textbook as a major source of instructional questions. Instead, they need to design supplementary questions to remedy the lack of higher level questions. Furthermore, Textbook developers should try to devise exercises and activities that go beyond lower-order cognitive skills and to include higher-order ones. Finally, it is recommended that other research studies be conducted on larger samples and in other areas in addition to reading. More research studies are needed in the area of transition from school to university in all fields of study.

\section{REFERENCES}

[1] Al-Haddad, A. (1996). Reading attitudes reported by twelfth grade students in Jordan. PhD dissertation, University of Nebraska.

[2] Alul, F. (2005). Analyzing English textbook questions for the elementary eight grade in Palestine Based on Bloom's Taxonomy of educational goal at its cognitive domain. MA Thesis, An-Najah National University.

[3] Barret, T., Smith, R. (1974). Teaching reading in the middle grades. MA: Addison-Wisley

[4] Bloom, B. (ed.). (1956). Taxonomy of educational objectives: The classification of educational goals: Handbook 1 cognitive domain. New York: David Mckay Co. Inc.

[5] Ewies, M.(2010). An analysis of questions recorded in the Islamic Education Textbooks for basic stage in the United Arab Emirates. MA Thesis, Yarmouk University.

[6] Haines, S. (2009). Action pack 11, Student's Book. London: York Press

[7] Haines, S. (2009). Action pack 12, Student's Book. London: York Press

[8] Hopper, C. (2009). Practicing college learning strategies. ( $5^{\text {th }}$ Ed). New York, NY: Houghton Mifflin.

[9] Igbaria, A. (2013). A Content analysis of the WH-questions in the EFL textbook of Horizons. International Education Studies 6. 7, 200-224.

[10] Hussein, B. (2012). Analysis of the real situation of teaching reading comprehension to first year Students at the Department of English Language and Literature at Al-Zaytoonah Private University of Jordan. Asian Social Science 8. 4, 237-253.

[11] Pearson, P., Johnson, D. (1978). Teaching reading comprehension. New York: Holt, Rinehart and Winston.

[12] Rawadieh, S. (1998). An analysis of the cognitive levels of questions in Jordanian secondary social studies textbooks according to Bloom's taxonomy. Ph. D dissertation, Ohio University. 
[13] Riazi,, A., Mosalanejad, N. (2010). Evaluation of learning objectives in Iranian high-school and pre-university English textbooks using Bloom's Taxonomy. The Electronic Journal for English as a Second Language, 13. 4, 1-16.

[14] Rinser, G., Nicholson, J., Webb, B. (2000). Cognitive levels of questioning demonstrated by new social studies textbooks: what the future hold for elementary students. Paper presented at The Annual Meeting of the Mid-south Educational Research Association, Bowling Green, KY, November 15-17.

[15] Soars, J., \& Soars, L. (2006). New Headway Plus. Oxford: Oxford University Press.

[16] Sunggingwati, D. (2003). Reading questions of junior high school English textbooks. Bahasa Dan Seni, 31.1, 84-105. http//:isjd.pdii.lipi.go.id/admin/journal/3110384105.pdf (accessed 17/3/ 2014).

[17] Underhill, N. (1991). Testing Spoken English. testing: A handbook of oral testing techniques. Cambridge: Cambridge University Press.

[18] Williams, E., \& Moran, C. (1989). Reading in a foreign language at intermediate and advanced levels with a particular reference to English. Language Teaching 22, 4, 217-228.

Nasser M. Freahat is an assistant professor of English Language Curricula and Instruction. He is teaching English language courses for graduate and undergraduate courses in the English Language Department at Imam Mohammad Ibn Saud Islamic University-Riyadh, Saudi Arbia. His research interests include Language Acquisition, Teaching Reading Comprehension, Discourse Analysis.

Oqlah M. Smadi is a professor of Applied Linguistics. He has been teaching English language courses for graduate and undergraduate students since 1980. He is now teaching graduate courses in the Department of English Language Curricula and Instruction at Yarmouk University- Irbid, Jordan. His research interests include First and Second Language Acquisition, TEFL and TAFL, Discourse Analysis and Pragmatics, Contrastive Analysis. 